\title{
IMAGE ENHANCEMENT CITRA ZOOM DENGAN MENGGUNAKAN METODE BILINEAR INTERPOLATION DARI KAMERA WEBCAM
}

\author{
Hendro Nugroho ${ }^{1)}$, Maftahatul Hakimah ${ }^{2)}$,Azmuri Wahyu Azinar ${ }^{3)}$ \\ 1), 2),3) Program Studi Teknik Informatika, Fakultas Teknologi Informasi, ITATS \\ Jl Arief Rachman Hakim 100, Surabaya \\ Email:dosh3ndro@itats.ac.id ${ }^{1)}$,
}

\begin{abstract}
Abstrak
Kamera Webcam yang terdapat komputer memiliki desain yang sangat simple menggunakan lensa standar. Penggunaan kamera Webcam untuk pengambilan citra yang akan di zoom akan menghasilkan efek aliasing atau efek blur. Untuk memperbaiki kualitas citra (Image Enhancement) menggunakan metode Bilinera Interpolation yang diakibatkan efek zoom pada citra, pada penelitian ini menggunakan beberapa tahapan yaitu: cropping, metode Bilinear Interpolation, dan output hasil. Untuk mengetahui hasil output Image Enhancement, maka dilakukan evaluasi yang menggunakan metode ekstraksi tekstur dengan menggunakan fitur Entropi untuk mengetahui tingkat sebaran piksel setelah di zoom atau sebelum di zoom. Hasil yang didapat untuk tahapan evaluasi pada Image Enhancement memiliki nilai yang sama, menunjukkan hasil citra yang di zoom dan sebelum di zoom memiliki kualitas sama atau tidak ada perubahan.
\end{abstract}

Kata kunci: Image Enhancement, Biliner Interpolation, Zoom, Ekstrasi Tekstur Fitur Entropi.

\section{Abstract}

Webcam that contains a computer has a very simple design using a standard lens. The use of a webcam is to capture images that will be zoomed will produce an aliasing or blur effect. To improve image quality (Image Enhancement) using the Bilinear Interpolation method due to zoom effect on image, in this study using several stages there are cropping, Bilinear Interpolation method, and output result. To find out the output of Image Enhancement, an evaluation is performed using texture extraction method by using Entropy feature to determine level of pixel distribution after or before zooming. The results obtained for evaluation stages in Image Enhancement have the same value, showing the image results being and before zoom has same quality or no change.

\section{Keywords: Image Enhancement, Biliner Interpolation, Zoom, Entropy Feature Texture Extraction.}

\section{PENDAHULUAN}

Bentuk kamera Webcam yang didesain sangat simple menggunakan lensa standar, yang terdiri papan sirkut untuk menangkap sinyal gambar. Hasil yang didapat pada kamera Webcam dari resolusi VGA atau resolusi pixel pada kamera Webcam, atau juga dibantu dari cahaya ruang disekelilingnya. Permasalahan yang didapat pada citra didapat dari resolusi rendah (Low Resolution) pada kamera Webcam atau mobile phone, apabila citra diperbesar (Zooming) maka menghasilkan efek aliasing yaitu ditemukan garis tepi zigzag (jaggies) atau efek blur (Bluring effects) [1]. Hasil citra blur atau tipe citra yang memiliki noise dapat menurunkan kualitas hasil citra yang tidak baik [2]. Dari permasalahan tersebut dibutuhkan perbaikan citra atau meningkatkan kualitas citra dengan proses Image Enhancement. Pendekatan metode dari permasalahan tersebut untuk melakukan pengujian perbaikan atau kualitas citra menggunakan metode Bilinear Interpolation untuk mengatasi gambar yang bergerigi. Selain itu Interpolasi juga digunakan dalam proses anti-aliasing pada citra [3].

Dari permasalahan diatas, maka dalam penelitian Image Enhancement menggunakan metode Interpolation Bilinear untuk perbaikan dari sebuah piksel yang berwarna dan intensitasnya didasarkan pada nilai-nilai di sekitar piksel. Semakin banyak yang diketahui tentang informasi di sekitar piksel, maka semakin baik dalam proses interpolation. Interpolation yang digunakan adalah Bilinear yang terbentuk berdasarkan kombinasi dari dua Linear Interpolation. Bilinear dapat melakukan pengadaan piksel berdasarkan piksel disekelilingnya[4]. Teknik Interpolation juga bisa digunakan pada citra zooming [6]. Untuk pengambilan data citra menggunakan kamera Webcam dilakukan di dalam ruangan dan di luar ruangan. Untuk waktu pengambil citra dilakukan pada siang dan malam, untuk malam hari dibantu dengan 
menggunakan lampu sebagai pencahayaannya. Setelah itu citra dilakukan proses cropping untuk memilih objek yang akan dilakukan proses zooming dengan skala 2x dan 3x. Untuk mengetahui tingkat keberhasilan penelitian ini dilakukan pengujian hasil proses Image Enhancement dengan metode Bilinear Interpolation dengan menggunakan ekstraksi tekstur berbasis Histogram. Fitur yang akan digunakan adalah Entropi. Fitur Entropi dapat mengetahui informasi sebaran piksel pada citra yang akan di zoom [5].

\section{DASAR TEORI}

\subsection{Image Enhancement}

Perbaikan kualitas citra (Image Enhancement) digunakan untuk menonjolkan beberapa aspek informasi yang terkandung dalam citra. Image Enhancement merupakan salah satu awal dalam pengolahan citra yang akan digunakan penelitian dalam hal meningkatkan kualitas citra yang akan diproses lebih lanjut. Perbaikan kualitas citra diperlukan karena sering kali citra yang dijadikan objek pembahasan mempunyai kualitas yang kurang baik.

Adapun proses yang termasuk ke dalam perbaikan kualitas citra antara lain :

- Pengubahan kecerahan citra

- Pengubahan kontras

- Pengubahan histogram citra

- Pelembutan citra

- Penajaman

- Pewarnaan semu

- Pengubahan Geometrik

\subsection{Citra Zoom}

Perbesaran citra (Zoom) digunakan untuk melakukan mengubah ukuran piksel citra menjadi lebih besar. Perbesaran citra dilakukan pada arah vertical citra (y), dan horizontal (x). persamaan untuk perbesaran citra dapat diasumsikan titik pusat $(0,0)$, dari lokasi asli $\mathrm{A}(\mathrm{x}, \mathrm{y})$ dikalikan dengan besaran skala Sx pada sumbu x dan Sy pada sumbu y

$$
Q_{(x, y)}=A_{(x, y)} * S_{(x, y)}
$$

\subsection{Bilinear Interpolation}

Interpolasi adalah metode dasar digunakan secara eksklusif dalam melakukan zooming, shrinking, rotating, dan geometric corrections [4]. Interpolasi citra bekerja dalan dua arah, dan mencoba untuk mencapai pendekatan yang terbaik dari sebuah piksel yang berwarna dan intensitasnya didasarkan pada nilai-nilai di sekitar piksel. Semakin banyak diketahui tentang informasi di sekitar piksel, maka semakin baik dalam interpolasi. Ada beberapa algoritma Interpolasi yaitu Algoritma Nearest Neighbor dan Algoritma Bilinear.

Bilinear Interpolation adalah algoritma yang melakukan penggandaan piksel berdasarkan piksel tetangga dekatnya, sehingga algoritma Bilinear menghasilkan citra digital yang lebih baik dibandingkan dengan hasil dari algoritma Ketetanggaan [4]. Persamaan menunjukkan cara menghitung nilai intensitas yang digunakan untuk suatu piksel berdasarkan empat piksel [5].

$$
f\left(p^{\prime}, q^{\prime}\right)=(1-a)[(1-b) f(p, q)+b f(p, q+1)]+a[(1-b) f(p+1, q)+b f(p+1, q+1)]
$$

\subsection{Ekstrasi Tekstur}

Tekstur pada citra adalah nilai yang terkandung dalam setiap citra dari sisi keteraturan pola dalam objek. Tekstur dapat dikategorikan ke dalam dua bentuk: 1) tekstur teratur dan 2) tekstur tidak teratur [5]. Metode yang digunakan untuk melakukan ekstrasi tekstur dengan menggunakan fitur Entropi untuk mengindikasikan kompleksitas citra, dengan menggunakan persamaaan sebagai berikut:

$$
\text { Entropi }=-\sum_{i=0}^{l-1} p(i) \log _{2}(p(i))
$$


Semakin tinggi nilai entropi, semakin kompleks citra tersebut, entropi juga merepresentasikan jumlah informasi yang terkandung di dalam sebaran data [5].

\section{METODOLOGI PENELITIAN}

Data citra yang diamati dari proses perbesaran citra (Zoom) dilakukan pada saat mendapatkan data citra dari pengambilan citra kamera Webcam. Setiap citra diperbesar sampai dengan ukuran skala 3 dari ukuran yang sebenarnya, sehingga mendapatkan efek bergerigi pada citra. Efek zigzag (jaggies/Aliased) pada citra terdapat pada objek citra yang diperbesar sehingga objek citra tidak kelihatan jelas (gambar 1).

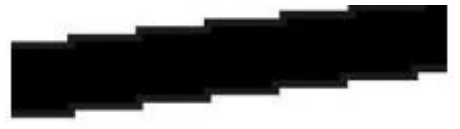

(a)

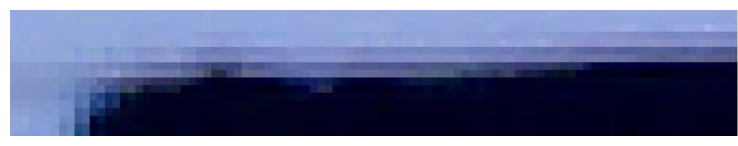

(b)

Gambar 1. (a) Garis yang mengalami Aliased, (b) Garis yang mengalami Anti-Aliased

Langkah-langkah dalam penelitian ini dapat dijelaskan adanya dua proses yaitu proses ujicoba dan proses evaluasi keberhasilan. Tahap-tahap pengerjaan penelitian ini dapat dilihat pada gambar 2. Dalam proses data ujicoba (testing) input citra dari kamera webcam dilakukan proses cropping untuk mengambil citra yang akan dilakukan proses zoom. Ukuran cropping bebas sesuai dengan objek yang diinginkan. Untuk proses zoom ditentukan ukuran citra perbesaran dalam bentuk piksel, selanjutnya dilakukan proses Bilinear Interpolation untuk memperbaiki hasil zoom, sebagai hasil output Image Enhancement.

Untuk memudahkan penghitungan nilai ekstraksi fitur pada tahap proses evaluasi, citra hasil image enhancement dilakukan proses perubahan warna citra dalam bentuk citra grayscale. Sehingga piksel yang didalam citra nilai RGB menjadi sama atau menjadi warna abu-abu. Dengan nilai citra RGB sama maka membantu kecepatan proses penghitungan nilai ekstraksi tekstur fitur Entropi. Proses evaluasi untuk mengetahui tingkat keberhasilan Image Enhancement dilakukan proses ekstraksi tekstur dangan fitur Entropi, nilai ekstraksi tekstur pada image enhancement ini untuk mengetahui jumlah informasi tentang sebaran data pada hasil image enhancement dan untuk membandingkan hasil sebelum citra di zoom dan setelah citra zoom, apakah mengalami perbedaan informasi data piksel yang ada pada citra.

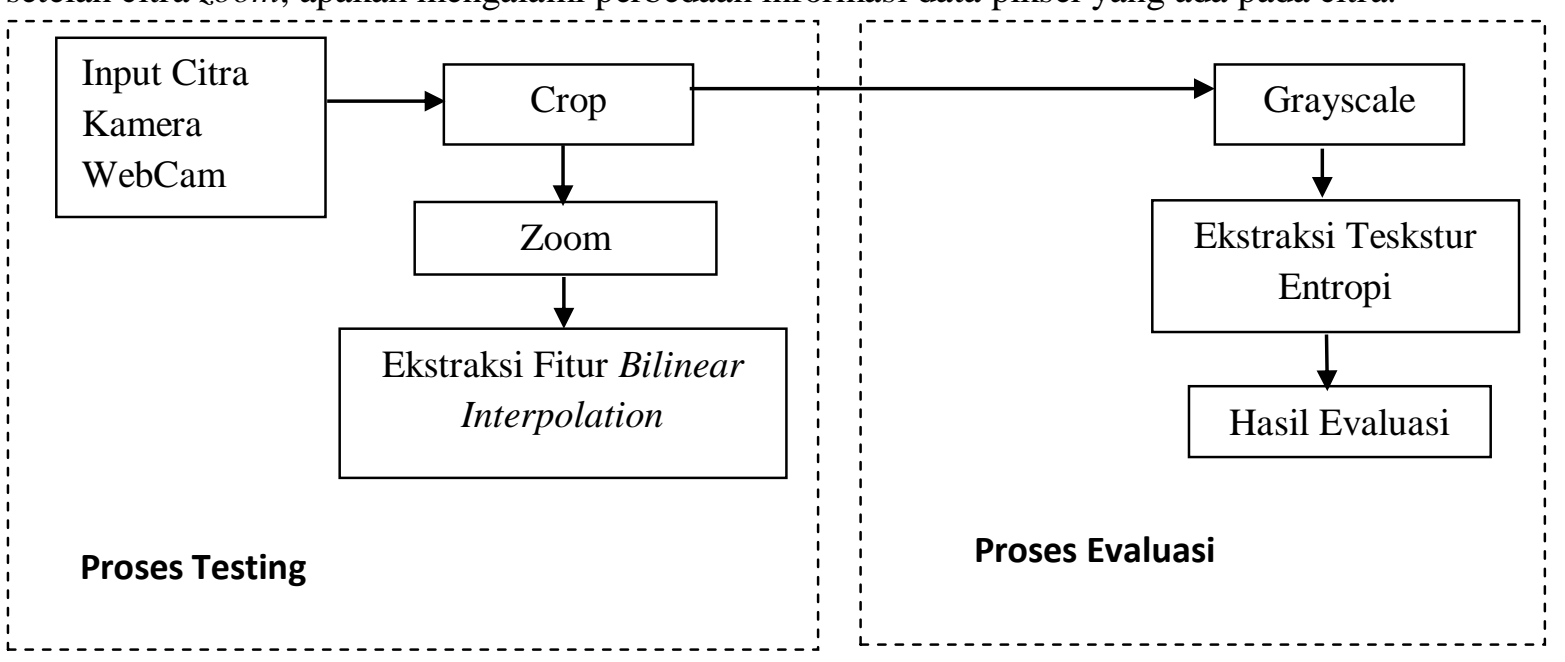

Gambar 2. System Image Enhancement

\section{HASIL DAN PEMBAHASAN}

Hasil penelitian yang sudah dilakukan adalah pembuatan aplikasi Image Enhancement yang digunakan untuk perbaikan citra Webcam yang dilakukan proses zoom. Didalam aplikasi image enhancement terdiri dari aplikasi pengujian dan aplikasi evaluasi untuk mengetahui tingkat keberhasilan citra. 


\subsection{Hasil Image Enhancement}

Pengujian dilakukan pada objek yang diambil dari kamera webcam didalam ruangan ataupun diluar ruangan pada siang hari atau terdapat cahaya yang dapat membantu objek terlihat. Contoh citra proses cropping diambil dari kamera webcam dengan jarak 1 meter ditunjukkan pada gambar 3.

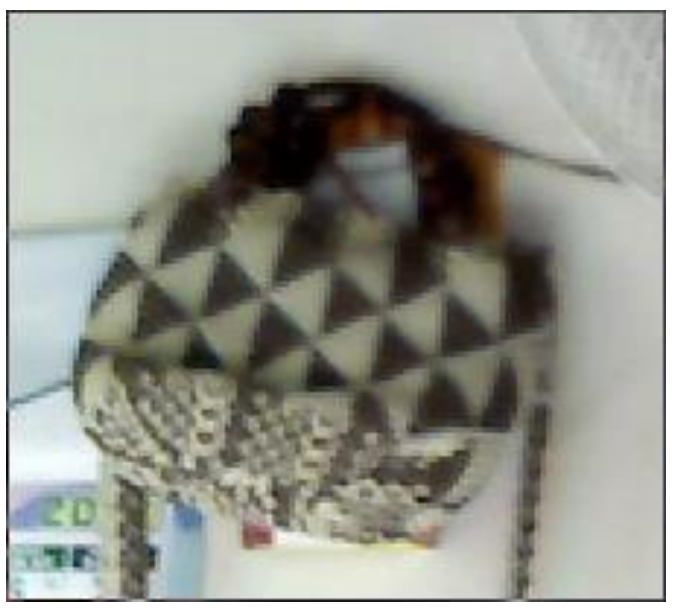

Gambar 3. Citra hasil Crop dari kamera Webcam

Pengambilan citra objek tas (gambar 3) didalam ruangan pada waktu siang menggunakan pencahayaan sinar matahari. Proses cropping digunakan untuk memilih objek yang akan diproses zoom. Contoh hasil proses zoom yang sudah dilakukan dengan menggunakan metode Bilinear Interpolation ditunjukkan pada gambar 4 .

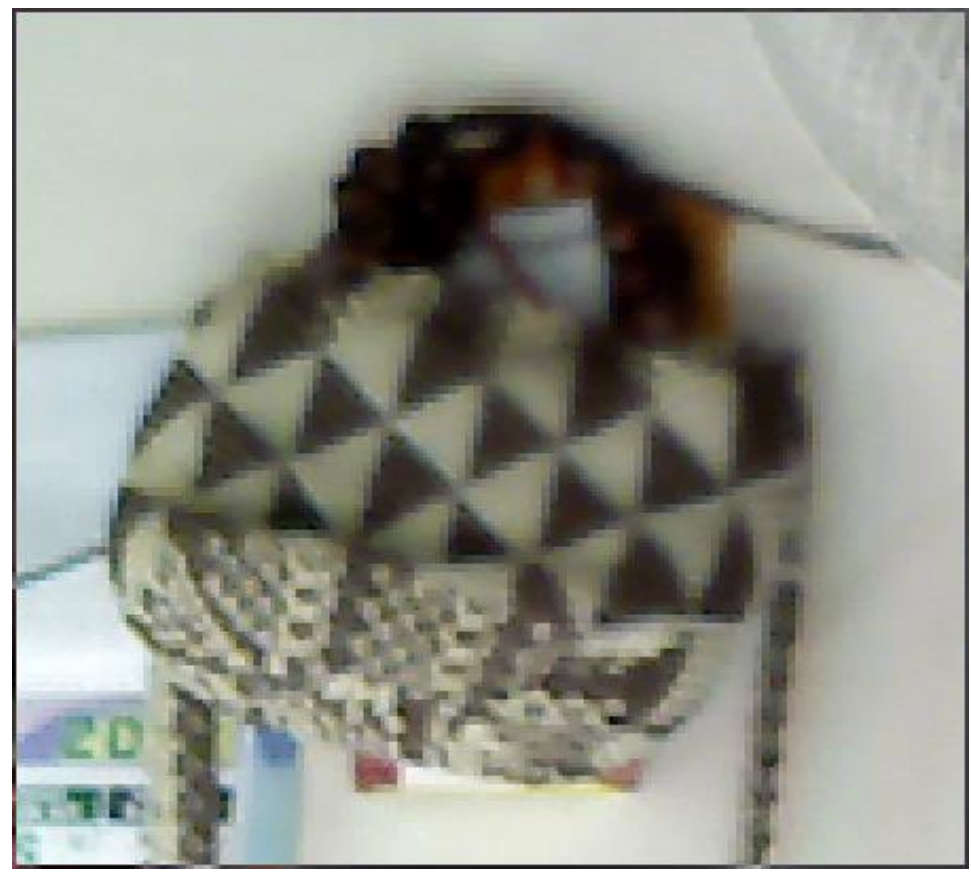

Gambar 4. Hasil citra Zoom Image Enhancement dengan metode Biliner Interpolation skala 2

Dari citra cropping gambar 3 dengan ukuran 226x203 piksel dilakukan proses zoom dengan skala 2 yang menjadi ukuran $452 \times 406$ piksel (gambar 4) yang perbesaran citra menggunakan persamaan 2. Sehingga hasil yang didapat menggunakan skala 3 maka ukurannya menjadi 678x609 piksel dan skala 4 menjadi $904 \times 812$ piksel. 
Proses Image Enhancement pada citra yang sudah di cropping yang ditunjukkan pada gambar 3 dan hasil Image Enhancement yang ditunjukkan pada gambar 4 terdapat bagian garis yang mengalami AntiAliased yang dicontohkan pada gambar 5 .

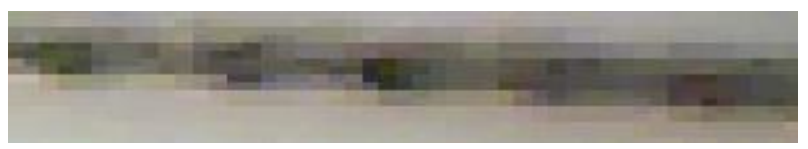

Gambar 5. Contoh bagian citra Anti-Aliased

\subsection{Mengukur Tingkat Keberhasilan}

Mengukur tingkat keberhasilan pada image enhancement dengan menggunakan metode biliner interpolation untuk mengetahui sebaran data informasi setiap piksel pada citra sebelum zoom atau sesudah zoom yang menggunakan ekstraksi tekstur citra fitur Entropi. Nilai-nilai ekstraksi tekstur fitur entropi ini digunakan untuk mengetahui apakah hasil proses sebelum dan sesudah proses zoom memiliki nilai yang sama. Sehingga penelitian ini proses image Enhancement pada zoom objek citra tidak mengalami perubahan.

Tabel 1. Ekstrasi Tekstur Fitur Entropi setelah Zoom Metode Bilinear Interpolation

\begin{tabular}{|c|c|c|c|}
\hline No & Ukuran Citra(piksel) & Skala S $_{(\mathbf{x}, \mathbf{y})}$ & Nilai Entropi \\
\hline 1 & $226 \times 203$ & Awal citra & 5,296948 \\
\hline 2 & $452 \times 406$ & 2 & 5,296948 \\
\hline 3 & $678 \times 609$ & 3 & 5,296948 \\
\hline 4 & $904 \times 812$ & 4 & 5,296948 \\
\hline
\end{tabular}

Perbandingan lain untuk menunjukan kinerja Image Enhancement metode Bilinear Interpolation pada citra yang di zoom dengan citra yang di zoom tanpa menggunakan metode Bilinear Interpolation ditunjukkan pada tabel 2.

Tabel 2. Ekstrasi Tekstur Fitur Entropi setelah Zoom tanpa Metode Biliner Interpolation

\begin{tabular}{|c|c|c|c|}
\hline No & Ukuran Citra(piksel) & Skala $\mathbf{S}_{(\mathbf{x}, \mathbf{y})}$ & Nilai Entropi \\
\hline 1 & $226 \times 203$ & Awal citra & 5,296948 \\
\hline 2 & $452 \times 406$ & 2 & 5,297537 \\
\hline \multicolumn{2}{|c|}{ Selisih } & $-0,000589$ \\
\hline
\end{tabular}

\subsection{Analisa Hasil}

Dari penyajian tabel 1 yang melakukan ekstraksi tekstur fitur entropi pada objek tas (gambar 3) menujukkan nilai entropi yang sama pada citra awal sebelum di zoom dan setelah di zoom dengan skala yang berbeda-beda. Ini menunjukkan Image Enhancement menggunakan metode Bilinear Interpolation kualitas citra setelah di zoom dan sebelum di zoom tidak ada yang berubah menunjukkan sebaran piksel yang didalam citra tetap sama walaupun ukuran citra sudah berubah. Untuk mengetahui perbandingan Image Enhancement pada citra yang di zoom menggunakan metode Bilinear Interpolation dengan tidak menggunakan metode Bilinear Interpolation dapat dilihat pada tabel 2. Hasil yang didapat adalah terdapat selisih nilai -0,000589. Dengan nilai negatif (-) menunjukkan ada peningkatan sebaran nilai piksel pada nilai piksel sebelum di zoom dan setelah di zoom, hasilnya menjadi beda.

\section{KESIMPULAN}

Pada penelitian ini Image Enhancement dengan menggunakan metode Bilinear Interpolation untuk citra yang di zoom dari kamera Webcam dihasilkan nilai yang sama pada citra sebelum di zoom dan setelah di zoom, ini menunjukan metode Bilinear Interpolation bisa memperbaiki citra (Image Enhancement). Perbaikkan citra yang di zoom tanpa menggunakan metode Bilinear Interpolation terdapat perbedaan sebaran piksel setelah di zoom dan sebelum di zoom, ini menunjukkan ada perbedaan kualitas yang setelah maupun sebelum di zoom. 


\section{DAFTAR PUSTAKA}

[1] M. P. T. G. Rajeet Roy, "Zooming Digital Images using Interpolation Techniques," International Journal of Application or Innovation in Enggineering and Management (IJAIEM), vol. 2, no. 4, 2013.

[2] P. K. M. Vaishalia Patel, "A Review on Different Image Interpolation Techniques for Image Enhancement," International Journal of Emerging Technology and Advanced Engineering (IJETAE), vol. 3, no. 12, 2013.

[3] V. M. Jaya, "Aplikasi Interpolasi Biliner pada Pengolahan Citra Digital," Program Studi Informatika Sekolah Teknik Elektro dan Informatika ITB, Bandung, 2013.

[4] F. Maulana, "Analisis dan Implementasi Penggunaan Metode Interpolasi Nearest Neighbor dan Interpolasi Bilinear (Studi Kasus Aplikasi Image Viewer Berbasis Android)," Naskah Publikasi AMIKOM Yogyakarta, Yogyakarta, 2013.

[5] S. A. Abdul Kadir, "Teori dan Aplikasi Pengolahan Citra," Yogyakarta, Andi Yogyakarta, 2013.

[6] S. Yanti Muda Oktaviana, Eksplorasi Informasi Arca Ganesha Museum Majapahit Tahun 2015, K. M. Majapahit, Ed., Mojokerto: Kementerian Pendidikan dan Kebudayaan Direktorat Jenderal Kebudayaan, 2015.

A. $\quad$ K. K. Theodoris. S, Pattern Recognition 3rd, S. d. A. Press, Ed., San Diego, 2006.

[7] Muntasa, Pengenalan Pola, Aplikasi Pengenalan Wajahm Analisis Tekstur Obyek, Pengenalan Plat Nomer Kendaraan, dan Segmentasi Pembuluh Darah, Yogakarta: Graha Ilmu Yogyakarta, 2015.

[8] S. S. Ritu Dhingra, "Comparison of Barious Interpolation Based Zooming Techniques," International Journal of Advanced Research in Computer Science and Software Engineering, vol. 3, no. 6, 2013. 